\title{
Characterization of compacted coal wash as structural fill material
}

\author{
B. Indraratna ${ }^{1}$, C. Rujikiatkamjorn ${ }^{2}$ and G. Chiaro ${ }^{3}$ \\ ${ }^{1}$ Professor and Head, School of Civil, Mining and Environmental Engineering, \\ Faculty of Engineering, University of Wollongong, Wollongong, NSW 2522, \\ Australia (corresponding author).E-mail: indra@uow.edu.au \\ ${ }^{2}$ Senior Lecturer, Centre for Geomechanics and Railway Engineering, School of \\ Civil, Mining and Environmental Engineering Faculty of Engineering, University of \\ Wollongong, Wollongong, NSW 2522, Australia. \\ ${ }^{3}$ Research Fellow, Centre for Geomechanics and Railway Engineering, School of \\ Civil, Mining and Environmental Engineering Faculty of Engineering, University of \\ Wollongong, Wollongong, NSW 2522, Australia.
}

\begin{abstract}
In this paper, detailed laboratory investigations were conducted on coal wash produced at coal mine, Wollongong, New South Wales, Australia. Geotechnical tests were conducted to determine the particle size distribution, compaction characteristics, shear resistance and collapse potential. The compaction tests were conducted under dry and submerged condition to examine the compactability and the strength of the coal wash. The test shows that compacted coal wash has good potential as effective fill for embankments, and land reclamation. Although when coal wash is compacted under submerged condition, increased level of compaction has minimal effect.
\end{abstract}

\section{INTRODUCTION}

Recently, there has been a trend towards a more environmentally conscious society. As a result, waste minimization and waste recycling have been given a high priority in Australian industry. Mine waste including coal wash and furnace slag has both a monetary and an environmental benefit over conventional fills, if properly utilised in large construction projects (Indraratna et al. 1994; Kamon and Katsumi 1994; Lim and Chu 2006). Wollongong City, New South Wales located in the heart of coal mining and steel industry generates a mammoth volume of coal wash, blast furnace slag, mine waste aggregates and other granular by-products more than any other Australian city. Port Kembla is Wollongong's commercial harbor that solely caters for the mining market. Due to the demand for port facilities, 45 hectares Outer Harbour adjacent to the existing port structures has been undergone major expansion via land reclamation to maximize the available land area in the port and to provide the maximum number of berths suitable for bulk cargoes and container handling to service regional importers and exporters. In Illawarra, large stockpiles of waste mine products such as coal wash and furnace slag have been produced 2.1 million tons per year. Due to the associated environmental concerns, the Port Kembla Port Corporation would consider the use of these locally abundant waste aggregates as the 
predominant reclamation fill, among the more conventional natural aggregates such as tunnel cuttings and used rail ballast from other parts of NSW.

Based the existing geological information (Stroud et al. 1985), the volcanic sandstone bedrock can be found at the bottom of Outer Harbor area (RL -15 to -20m), while the thickness of the estuarine clay is relatively small. The type of reclamation fills used at Port Kembla would constitute a relatively important component of the total settlement, apart from the obvious implications on the load bearing capacity and long term settlement. If the port foundations are not properly stabilized, unacceptable settlement of fill material, sudden subsidence of granular media, large lateral displacements and differential movements can cause damage to the main structures, as well as to adjacent facilities (pipelines, retaining walls etc.). The improvement of the heterogeneous waste materials of coal wash in terms of geotechnical properties has been conducted in the past (Indraratna 1994; Sarsby 2000; Pusadkar and Ramaswamy, 2005). Compaction method has been found to be useful to improve the load-deformation behavior (stiffness) of underlying of soil layers, especially loose granular materials (Kettle, 1983, Koutsoftas and Keifer, 1990; Pan and Selby, 2002, Lee and $\mathrm{Gu}, 2004)$.

It is generally acknowledged that granular waste fill can be effectively compacted in the field using dynamic compaction. Compaction rapidly decreases the soil porosity via mechanical energy thereby improving the engineering properties of soil including friction angle and elastic modulus. However, there is no past study conducted to evaluate the geotechnical properties of coal wash upon compaction in relation to shear strength and collapsibility potential above or below water table. According to Indraratna et al. (1994) the collapse mechanism is controlled by three factors; (a) potentially unstable structure, such as flocculent type associated with soils compacted dry of optimum; (2) a high applied pressure which further increases the instability; and (3) a high suction which provides the structure with only temporary strength which dissipates on wetting. Evaluating the compaction characteristics of coal wash remain to be a most fundamental and essential component of this study.

\section{COAL WASH CLASSIFICATION}

The coal wash is a waste by-product of coal mining operations in the Illawarra. It is produced by the coal washery process used to refine raw, run-of-mine coal material. The properties of coal wash are not uniform because the mineral components are likely to vary from one place to another. Figure 1 shows the coal wash sample used in the testing program. The coal wash sample is a well graded, black, heterogeneous soil with varying constituent elements including coal. These constituents depend on the nature of the surrounding geology and mining processes used. This consists of any rock or soil strata local to the coal seam being mined. Table The specific gravity of coal wash sample is 2.04. The plastic and liquid limits are $17.7 \%$ and $27.2 \%$, respectively.

The sieve analysis was conducted according to ASTM standards. The grain size distribution of the coal wash is shown in Fig. 2. Based on the Unified Soil 
Classification System, the coal wash can be categorized as well graded sand (SW) with a uniformity coefficient of $10-12$. The $\mathrm{D}_{50}$ size is in the order of $2.5 \mathrm{~mm}$, and the largest $20 \%$ of the particle fraction in the range of $6-10 \mathrm{~mm}$.

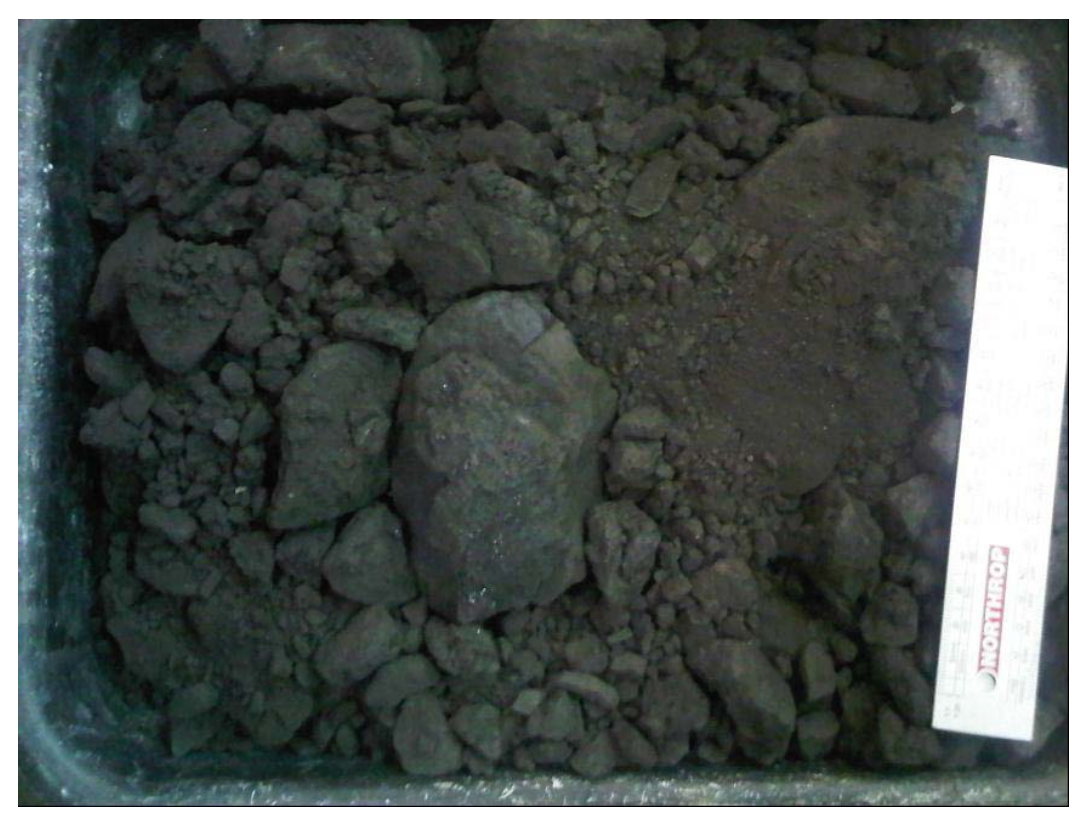

Figure 1. Coal wash sample

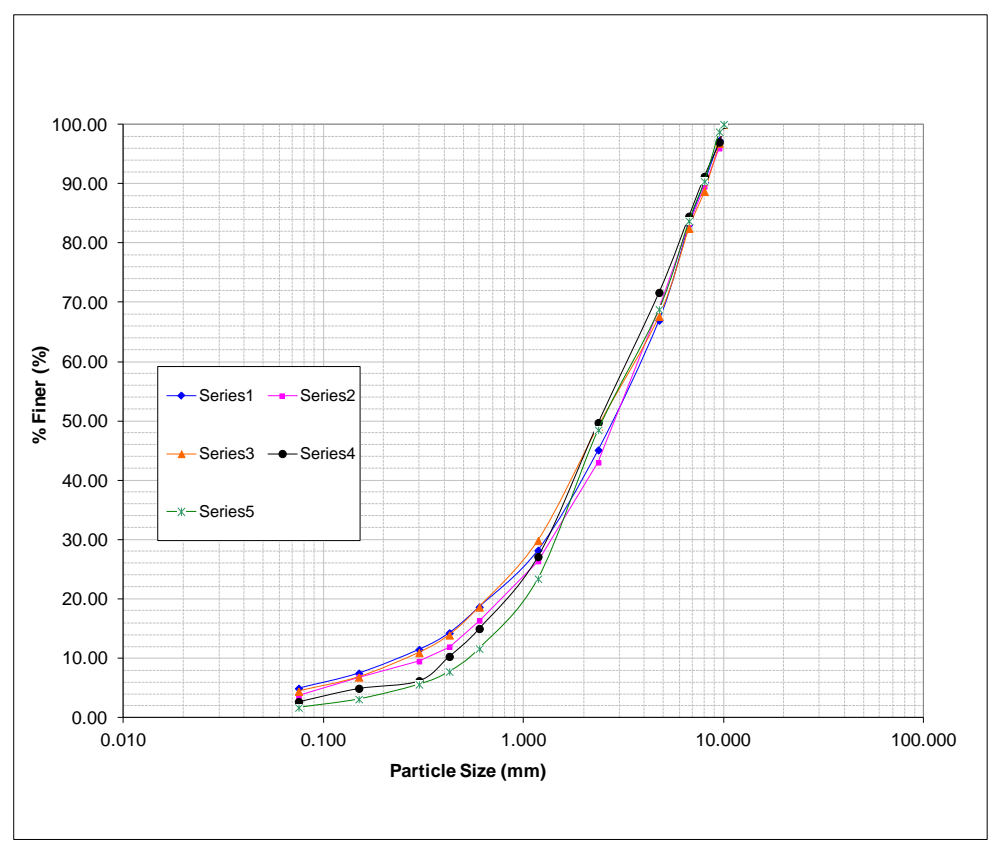

Figure 2. Particle size distribution curve of coal wash 


\section{SAMPLE PREPARATION}

Laboratory tests on coal wash conducted to evaluate its engineering properties include the following: compaction efficiency by standard Proctor method, degradation after compaction; permeability test; strength parameters using unconfined compression test; and collapse potential using modified oedometer test. The preparation of coal wash specimens for laboratory testing is discussed below.

Compacted samples were sieved to remove particle larger than $10 \mathrm{~mm}$ and later subjected to compactive energy level. The samples were then used to conduct permeability test. To investigate the influence of compaction environment in the land reclamation on the compressive strength, the samples were prepared under both standard and modified Proctor compaction energy under submerged condition. For uniaxial compression test, relatively smaller completely dry sample with maximum particle size of $2.5 \mathrm{~mm}$ was used to avoid boundary effect. For the unconfined compression tests, the specimens were tested using standard strain-controlled machine with a displacement rate of $0.5 \mathrm{~mm} / \mathrm{min}$. To investigate the collapse settlement behavior of the coal wash, two series of tests conducted using the standard oedometer tests with drainage at both ends were as follows: (a) Non-compacted (loose) samples: the dry samples were loosely filled in the oedometer ring to achieve a dry density of $1000 \mathrm{~kg} / \mathrm{m}^{3}$, and (b) Compacted samples: the samples compacted with an optimum moisture content of $10.4 \%$ to obtain a dry density of $1645 \mathrm{~kg} / \mathrm{m}^{3}$ using mini compaction apparatus (Fig. 3).

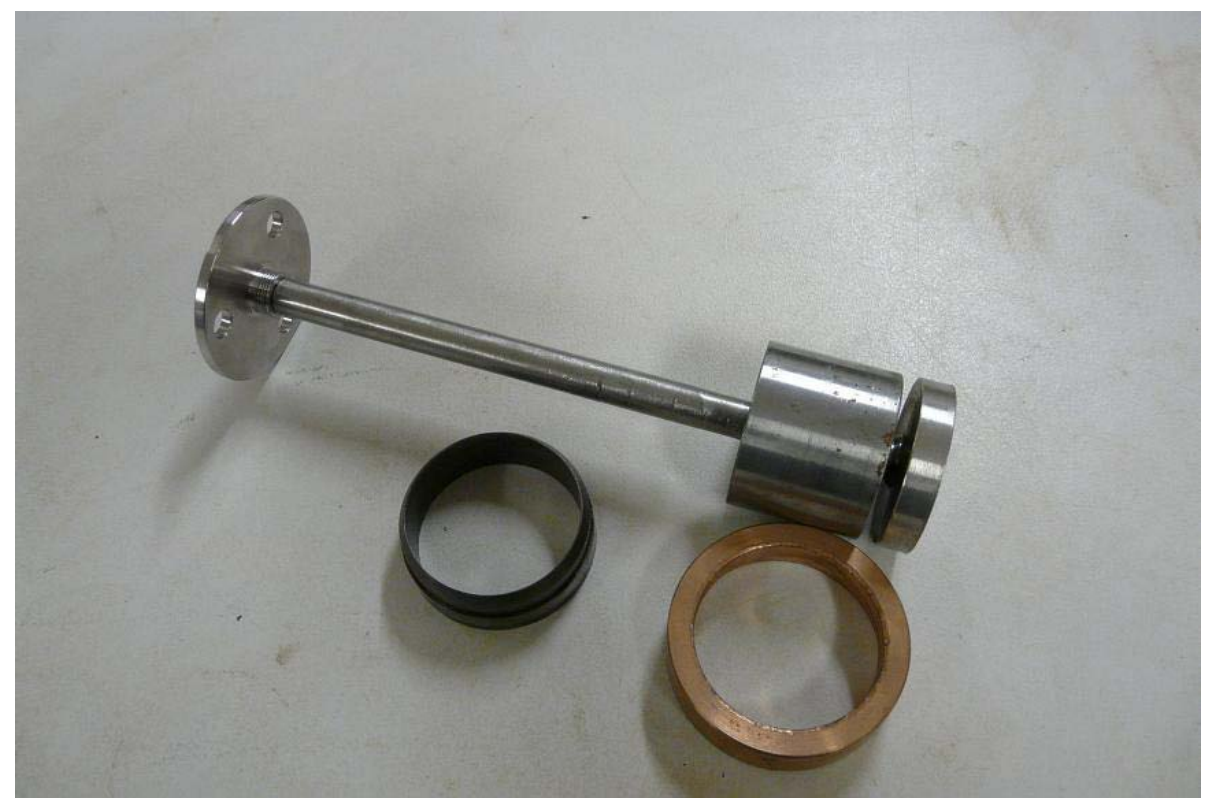

Figure 3. Mini Compaction Hammer with sample ring and ring guide 


\section{TEST RESULTS AND DISCUSSIONS}

\section{Compaction characteristics}

Figure 4 shows the dry density-moisture content curve with zero and $5 \%$ air void lines. The maximum dry density and the optimum moisture content for compacted coal wash are $1645 \mathrm{~kg} / \mathrm{m}^{3}$ and $10.4 \%$, respectively. The relative low maximum dry density compared to the conventional fill can be attributed to a lower specific gravity of 2.04. The long term settlement below compacted coal wash embankment can be effectively controlled because of its low dry density. In the field the moisture content must be restricted to $9-12 \%$ to achieve dry density close to maximum. This shows that coal wash can be easily compacted with conventional equipment over a wide range of the moisture contents.

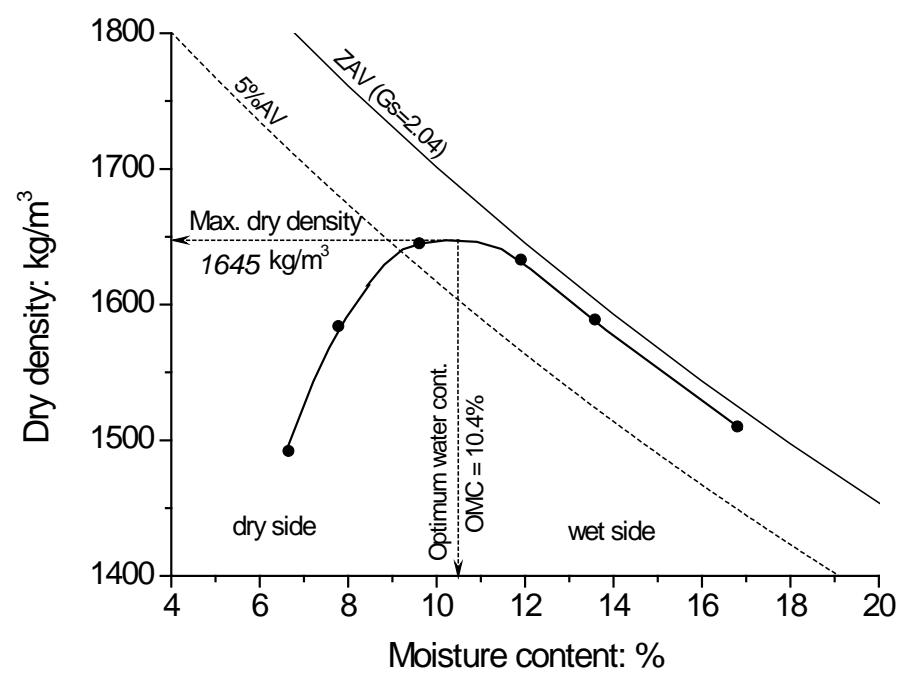

Figure 4. Dry density-moisture content relationships for coal wash

\section{Permeability}

Figure 5 presents the permeability-moisture content relationship obtained from 6 compacted specimens. The permeability varies between $10^{-8}$ to $10^{-9} \mathrm{~m} / \mathrm{s}$ which is comparable to low permeability clay. The permeability decreases with the moisture content up to about $12 \%$, and thereafter increases again gradually. For all compacted samples, the measured permeability is very small, and this is advantageous in the view point of minimizing internal seepage and erosion. The main reason for this low permeability can be attributed to the well-graded nature of the aggregates and the good compaction properties that are comparable to silty sand. This behaviour can be associated with different microstructures of compacted soil specimens and the corresponding arrangement of grains. The role of particle arrangement in compacted soils. As coal wash contains a significant fraction of fine particles, the mechanisms which attract and repulse fines within the micro-structure will play an important role. 
At low water content (i.e. dry of OMC), attractive forces between fine particles predominate, creating a flocculated structure with a random orientation. The addition of water increases the repulsion between particles leading them to assume a more parallel orientation. If compacted under conditions greater than OMC (i.e. wet of $\mathrm{OMC}$ ), the occurrence of parallel orientation is further enhanced, which leads to a dispersed structure.

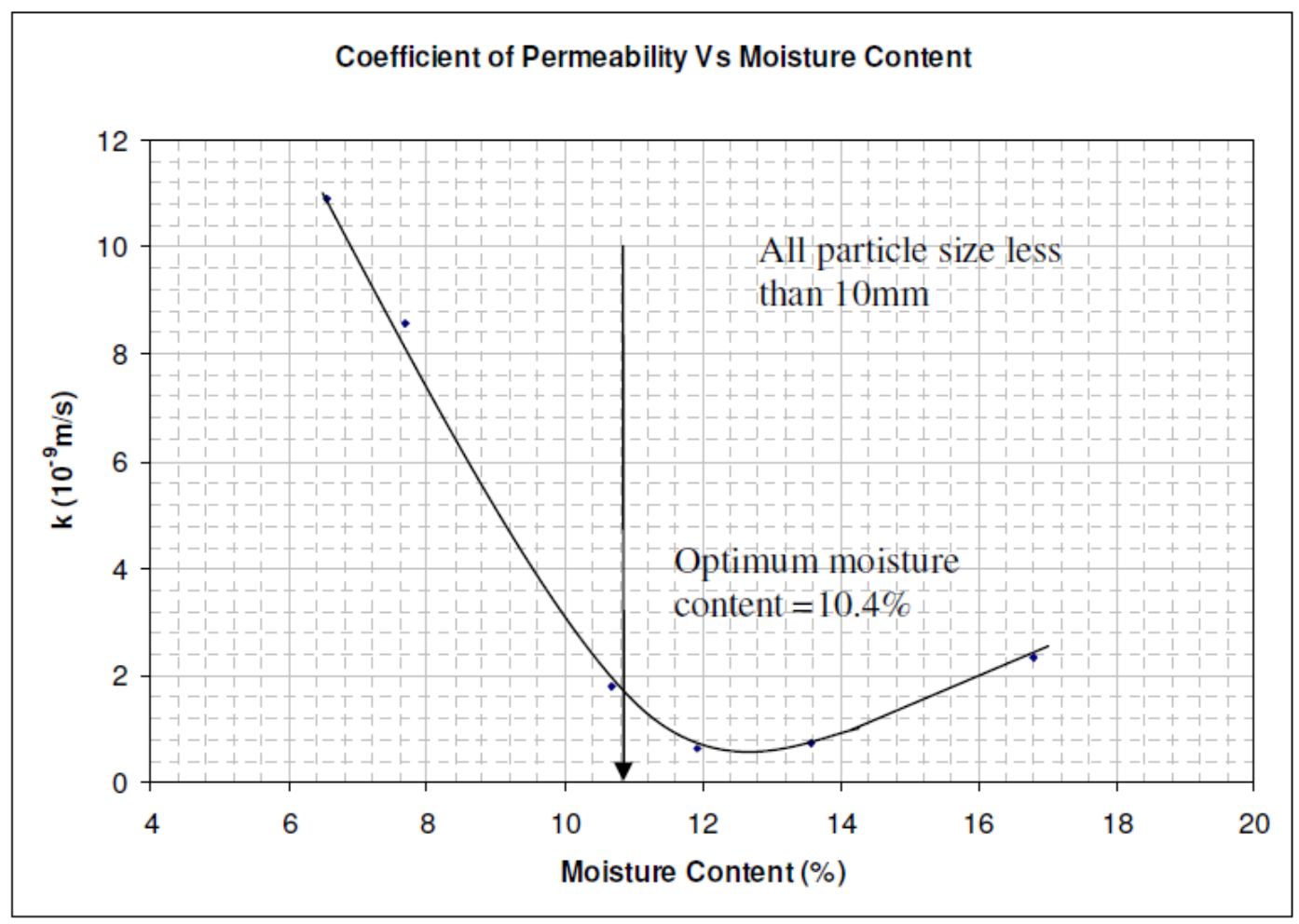

Figure 5. Permeability and moisture relationship after compaction

\section{Unconfined Compressive Strength Test}

To investigate the influence of compaction on the compressive strength, the samples were prepared under (a) standard compaction to represent "above water" relatively dry environment and (b) submerged condition. The samples were subjected to shearing immediately after compaction. Figure 6 shows the undrained shear strength of coal wash. The undrained shear strength is assumed to be half of the unconfined compressive strength. For compaction under dryer condition, the maximum undrained shear strengths vary between $10-100 \mathrm{kPa}$ depending on the moisture content. Therefore, it seems that in the compaction of these coal wash samples, the field compaction should be maintained close to the OMC, but preferably on the wetter side of the OMC, because, the drop in undrained shear strength rate on the dryer side is apparently substantial. The undrained shear strengths upon submergence are in the range of 5-10 $\mathrm{kPa}$ regardless of the compacted energy, these 
values are significantly below the undrained shear strength of samples compacted under standard compaction conditions.

\section{Collapse potential}

The collapse potential can be determined based on the volume change that occurs when a dry soil is submerged under water. It is usually obtained by conducting oedometer tests on soil specimen. The collapse potential is expressed as a change in void ratio on wetting compared to the pre-wetting volume of the soil at any stress level (Indraratna et al. 1994). An indication of the collapse potential $\left(C_{p}\right)$, as a function of the initial void ratio $\left(e_{0}\right)$ and the change in void ratio $(\delta e)$ is defined by:

$$
C_{p}=\delta e /\left(1+e_{0}\right)
$$

Figure 7 presents the collapse settlement and collapse potential during compression. It can be seen that the collapse potential increases when the vertical stress becomes larger. At points of flooding, the instantaneous compression is significant for uncompacted specimens at high vertical stress. For compacted specimens, instantaneous compression upon inundation is suppressed significantly. The collapse potential ranges from 0.01-0.06 for non-compacted specimen that can be categorized as a medium to high collapsible soil. However, after compaction, the collapse potential is in the range of $0.05-0.025$ which can be a representative of a medium collapsible soil. Hausmann (1990) stated that the collapse potential of a loose and dense sand are 0.05-0.1 and 0.01-0.02, respectively. It can be seen that the collapse behavior of compacted sand is comparable to densely compacted sand. Therefore, if the embankment constructed with coal wash is properly compacted, there should not be any problem of sudden deformation during the heavy rainfall or the rise of the sea level. In this regard, the coal wash can be regarded as an appropriate structural fill.

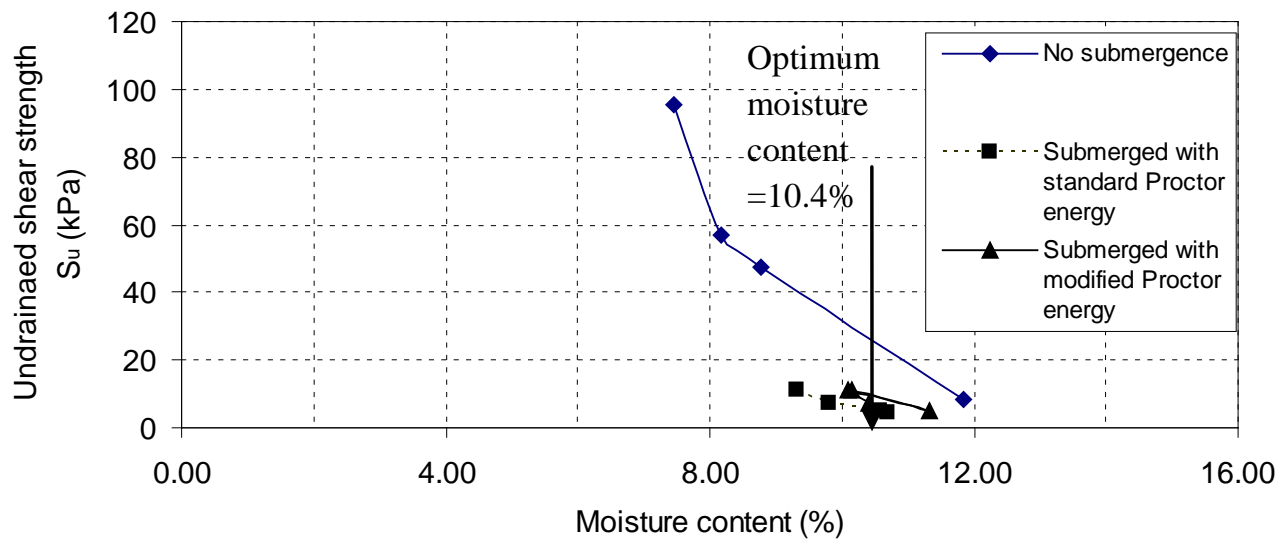

Figure 6. Undrained shear strengths of coal wash samples compacted under dry and submerged condition 


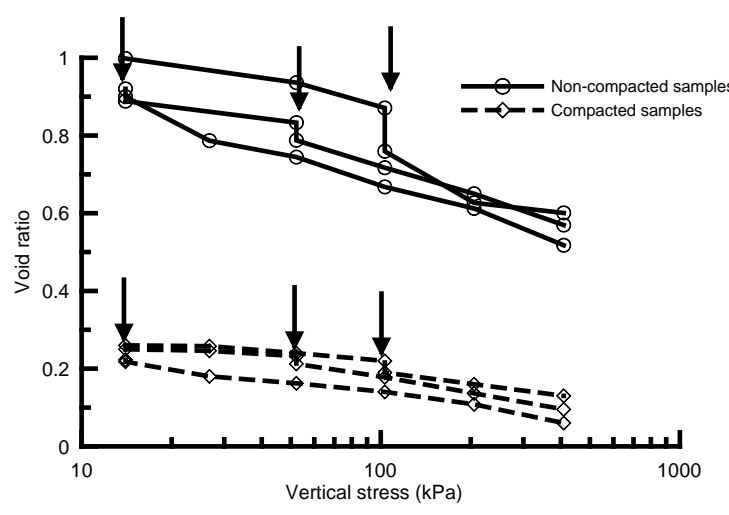

(a)

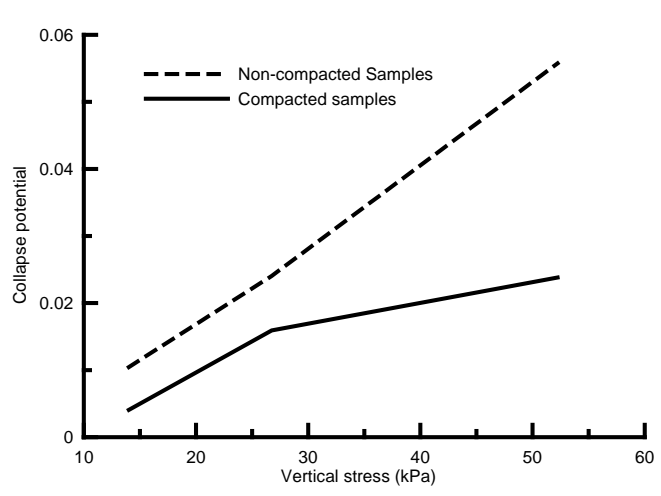

(b)

\section{Figure 7. (a) Collapse settlements during compression (Arrows indicate inundation) and (b) Collapse potential during compression}

\section{CONCLUSIONS}

Coal wash investigated in this study can be categorized as a well-graded sand (SW) based on the Unified Soil Classification System. If properly compacted, the coal wash can yield a maximum dry density more than $1600 \mathrm{~kg} / \mathrm{m}^{3}$ at the optimum moisture content approximately $10 \%$. The relative low maximum dry density can be attributed to a lower specific gravity of 2.04, due to a large amount of coal particles. This implies that long term settlement below compacted coal wash embankment can be effectively controlled because of its low dry density. The compaction of coal wash can be controlled easily with conventional field machinery in the wide range of moisture content between $9 \%$ and $12 \%$.

The well-compacted coal-wash permeability varies between $10^{-8}$ and $10^{-9} \mathrm{~m} / \mathrm{s}$ which is comparable to low permeability soil such as clay. The low permeability of compacted coal wash suggests the suitability for the construction of land reclamation to prevent any abrupt change in water table inside the embankment due to the change in sea level. In terms of shear strength, when coal wash is compacted under relatively dry condition representing above water level condition, the undrained shear strengths vary between $10-100 \mathrm{kPa}$. Unlike 'dry compaction', when coal wash is compacted under submerged condition, increased level of compaction has minimal effect. The undrained shear strengths upon submergence are in the range of 5-10 kPa regardless of the compacted energy, these values are significantly below the undrained shear strength of samples compacted under conventional dry conditions. The collapse potential of coal wash can be minimize by 1.5-2 folds when it is compacted close to the optimum moisture content. The collapse potential of compacted coal wash is comparable to densely compacted sand. 


\section{ACKNOWLEDGEMENT}

The Authors gratefully acknowledge the financial assistance from Australian Research Council, BHP Billiton-Illawarra Coal and Port Kembla Port Corporation.

\section{REFERENCES}

Hausmann, M. (1990). Engineering principles of ground modification, McGraw Hill, New York.

Indraratna, B. (1994). Geotechnical Characterization of Blended Coal Tailings for Construction and Rehabilitation Work. Quarterly Journal of Engineering Geology, British Geological Society, Vol. 27, No. 4, pp. 353-361.

Indraratna, B., Gasson, I., and Chowdury, R.N. (1994). Utilization of Compacted Coal Tailings as a Structural Fill, Canadian Geotechnical Journal, Vol. 31, October issue, 614-623.

Kamon, M. and Katsumi, T. (1994) Civil engineering use of industrial waste in Japan. Proceedings of the International Symposium on Developments in Geotechnical Engineering, Bangkok, Thailand, 265-278.

Kettle, R. J., (1983). The improvement of colliery spoil. Quarterly Journal of Engineering Geology, 16(3) 221-230.

Koutsoftas, D. C. and Keifer, M. L. (1990). Improvement of mine spoils in southern Illinois, Geotechnics of wastefill, Theory and Practice, 153-167.

Lee, F. H. and Gu, Q. (2004), Methods of estimating dynamic compaction effect on sand, Journal of Geotechnical and Geo-environmental Engineering, 130(2) 139152.

Lim, T. and Chu, J. (2006) Assessment of use of spent copper slag for land reclamation, Waste Manage Res. 24, 67-73.

Pan, J. L. and Selby, A. R. (2002). Simulation of dynamic compaction of loose granular soils, Advances in Engineering Software 33, 631-640.

Pusadkar, S. S. and Ramaswamy, G. (2005). Collapse behavior of compacted coal ash fill, Geotechnical Testing Journal, 28(3): 1:8.

Sarsby, R. (2000) Environmental Geotechnics. Thomas Telford Ltd., London, UK .

Stroud, W.J., Sherwin L., Roy H.N. and Baker C.J., (1985), Wollongong - Port Hacking 1:100 000 Geological Sheet 9029-9129, 1st edition. Geological Survey of New South Wales, Sydney. 